\title{
Productivity and economic assessment of wave energy projects through operational simulations
}

\author{
Boris Teillant $^{\mathrm{a}, *}$, Ronan Costello ${ }^{\mathrm{a}}$, Jochem Weber $^{\mathrm{b}}$, John Ringwood ${ }^{\mathrm{a}}$ \\ ${ }^{a}$ Center for Ocean Energy Research, National University of Ireland Maynooth, Maynooth, Co. Kildare, Ireland \\ ${ }^{\mathrm{b}}$ Wavebob Ltd. H3, Maynooth Business Campus, Maynooth, Co. Kildare, Ireland
}

\section{A R T I C L E I N F O}

\section{Article history:}

Received 30 November 2011

Accepted 4 May 2012

Available online xxx

\section{Keywords:}

Wave energy

Operational simulations

Productivity

Costs

Economic value

\begin{abstract}
A B S T R A C T
In this work, we present a methodology for the assessment of the economic value of ocean wave energy schemes. Such an assessment is a necessary tool for supporting investment decisions in the development of wave farms and in the development of wave energy converter (WEC) technology. To overcome the lack of operational experience, the methodology presented includes detailed operational simulations which relate the operational costs and the availability of the plant for power production to the characteristics of the device, the location, and the maintenance strategy chosen. The methodology consists of firstly, a productivity and costs assessment which embodies the operational simulations and secondly, a financial calculator which employs discounted cash-flow techniques to produce selected economic indicators. A case study, consisting of one hundred WECs units deployed off the West Coast of Ireland, is presented to exemplify the use of the methodology. The paper also explores how the key inputs to the assessment affect the economic performance of the case study project via a sensitivity analysis.
\end{abstract}

(c) 2012 Elsevier Ltd. All rights reserved.

\section{Introduction}

The ocean wave energy sector, given sufficient investment, has the potential to make a significant contribution to global electricity generation [1]. The realisation of this potential, in addition to facilitating efforts to de-carbonise and to diversify energy supply, represents a significant commercial opportunity. To date, however, no wave energy converter technology has been shown to support cost effective electricity generation; further research and development is required.

A method for assessment of the economic performance of wave energy projects is an indispensable tool; to wave farm project developers, in supporting investment decisions and in discriminating between alternative technologies; to prospective investors in technology companies in assessing the value of any particular WEC technology and, to technology developers, as a component of a techno-economic analysis, in directing the technology development decisions to best improve performance.

To date, most of the economic studies of WECs employ methodologies based on the cost of energy ( $\mathrm{CoE}$ ) approach. In the early 90's, Atkins Ltd. [2] and Thorpe [3] pioneered the investigation of CoE delivered by different WECs. The CoE approach consists of

\footnotetext{
* Corresponding author. Tel.: +353 876111007; fax: +353 17086027.

E-mail address: boris.teillant@eeng.nuim.ie (B. Teillant).
}

determining the unit electricity production cost, for example in Euro per kWh. Firstly, the capital and the operational costs of one particular technology are assessed. In calculating costs, several estimates based on expert quotations, generally supplied by a firm of engineering consultants, are considered. Secondly, the productivity is quantified. The ratio between the costs associated with one design and its predicted energy performance gives the CoE. More recently the $\mathrm{CoE}$ approach has been refined by several researchers, for instance, by applying discounting techniques to the future costs and energy production in order to obtain the levelised cost of energy (LCoE) [4-9].

Alternatively, Stallard et al. [10] developed a tool that facilitates direct economic comparison between various concepts, where drivers for the operation and maintenance schedule influence both the device availability and the operational costs. Equimar [11] and Carbon Trust [6] also recommend the use of well-established methods such as the present value approach, for assessing the economic performance of wave energy conversion projects.

In some western European countries, the provision of a price support which guarantees projects a higher than market price for renewable energy produced (e.g. in the UK, the Renewables Obligations Certificate, ROC) have resulted in substantial investment in recent years, primarily in wind and solar energy [12]. Higher levels of supports for wave energy than for wind energy, with a view to attracting the private investment necessary to initiate large scale wave farm deployment, have been proposed in 
Ireland, Scotland and Portugal. In such a political and financial context, it seems that the analysis of the economic viability of wave energy is better made, on the basis of the profitability of wave farm projects rather than, for example, on the basis of the performance of a single device or on the basis of an analysis of any country's national capacity, since it is on the basis of the profitability of wave farm projects that the crucial investment decisions will be made.

A particular difficulty in attempting to quantify the profitability of a wave energy project is the almost complete lack of operational experience in the sector; this results in estimates of operational costs and device availability which, at best, are associated with a high level of uncertainty and, at worst, are arbitrary. To address this difficulty, operational simulations which draw on the experience of industries that carry out similar activities, such as offshore wind and oil and gas exploration, can be used to assess the costs and effectiveness associated with a particular wave farm operation and maintenance strategy.

In this paper, a novel productivity and economic assessment of a wave energy project is presented. The assessment is focused on wave farm profitability and makes use of detailed operational simulations. The operational simulations have been developed expressly to generate estimates of operational costs and device availability which reflect device characteristics and any chosen operation and maintenance strategy. In contrast to the majority of the published economic investigations of wave energy, our model seeks to include a quantification of the costs associated with all the phases of a wave energy project from manufacture to decommissioning.

A top level schematic of our assessment is given in Fig. 1. The assessment comprises, firstly, a combined productivity and costs assessment which performs quantification of the capital expenditure (CapEx), operational expenditure (OpEx) and the energy productivity over the project lifetime and, secondly, a financial calculator which returns selected financial indicators. The required inputs to the combined productivity and costs assessment are:

1. The cost drivers, for example, the structural specification and the selection of power transmission equipment,

2. information on reliability,

3. information on the power generation performance of the system,

4. and, wave data measurements.

The financial calculator uses a discounted cash flow analysis and the indicators which it is capable of producing include: net present value (NPV), discounted pay-back period (DPBP), internal rate of return (IRR), and levelised cost of energy (LCoE).

The paper proceeds as follows. Initially, Section 2 articulates the framework and describes the main features offered by our model. Subsequently, Section 3 illustrates the capabilities of our model via a case study with computational benchmarks exemplifying the use of our model. Finally, we explore how key input factors are affecting the outcome of our model via a sensitivity analysis.

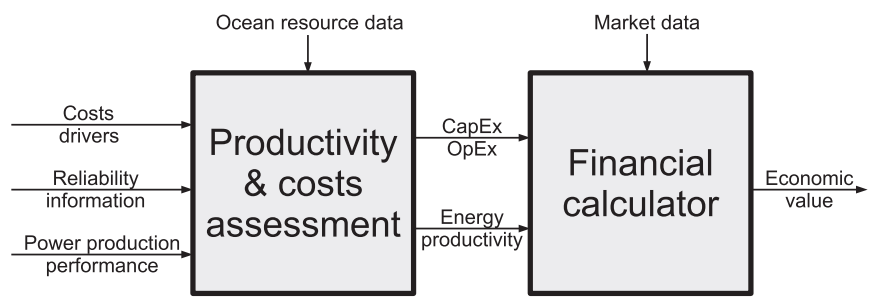

Fig. 1. Top level schematic of the productivity and economic assessment.

\section{Model}

As suggested by Weber et al. [13], an application scenario for WEC system technology, satisfying conceptual, technical and economical requirements, should address the entire lifecycle representation of the system.

Inputs for our model rely on the WEC design specifications, wave resource and market data. The design specification is generated by an engineering analysis which computes:

1. From dynamic simulations of the device, the power production data for relevant sea states, defined by the couple significant wave height $H_{s}$ and peak spectral period $T_{p}$ (or wave energy period $T_{e}$ ), in the form of a power matrix.

2. The relevant CapEx drivers from a structural analysis and from an analysis of the power transmission chain and other equipment.

3. A failure modes and effects analysis (FMEA), which describes possible failure events.

Within the productivity and cost assessment, the total manufacturing and installation costs are assessed and respectively termed the dry CapEx and wet CapEx. In addition, the calculation of the time slots where marine operations are permitted leads to the formulation of weather windows. Finally, the total CapEx and OpEx and the energy productivity are input to a financial algorithm for economic performance assessment. Fig. 2 shows how the core submodels of our model are connected. The model is designed for the simulation of a commercial full scale deployment of a wave farm (typically rated at 10's of MW).

\subsection{Inputs to the productivity and costs assessment}

\subsubsection{Sea characteristics}

The sea characteristics follow an initial resource assessment of the site chosen which allows an hourly description of the sea state over the project duration by reflecting the seasonal variation. Input for the model can be in the form of raw surface elevation time series or statistical summary wave data. Additionally, other site characteristics required include the distance between the site and the port as well as the water depth at the site.

\subsubsection{Vessel characteristics}

Our model makes use of published data from offshore ship and service industries, to capture information relevant to the day price of vessel hire and the purchase cost of support vessels. Furthermore, the specification of the vessels, such as their speeds under various sea and weight conditions, and their safety requirements, are also input to the model. When assessing the costs of installation, maintenance and removal activities for a WEC, the type of vessel required and the duration of the operations are the main drivers [14].

\subsubsection{Device characteristics}

The device engineering analysis includes information pertaining to the specification, reliability and performance of the device. Firstly, the design specification provides explicit information about the characteristics of the WEC such as its geometric dimensions and its mechanical and electrical characteristics and constraints. Secondly, the technical production performance of the device is summarized in the power matrix. The power matrix lists the energy production rates of the WEC for different relevant sea state parameters in the form of a table. Lastly, the reliability of each subcomponent of the WEC is specified under an FMEA table which lists the likelihood of failure of each component involved in the project along with the requirements for the repair. 


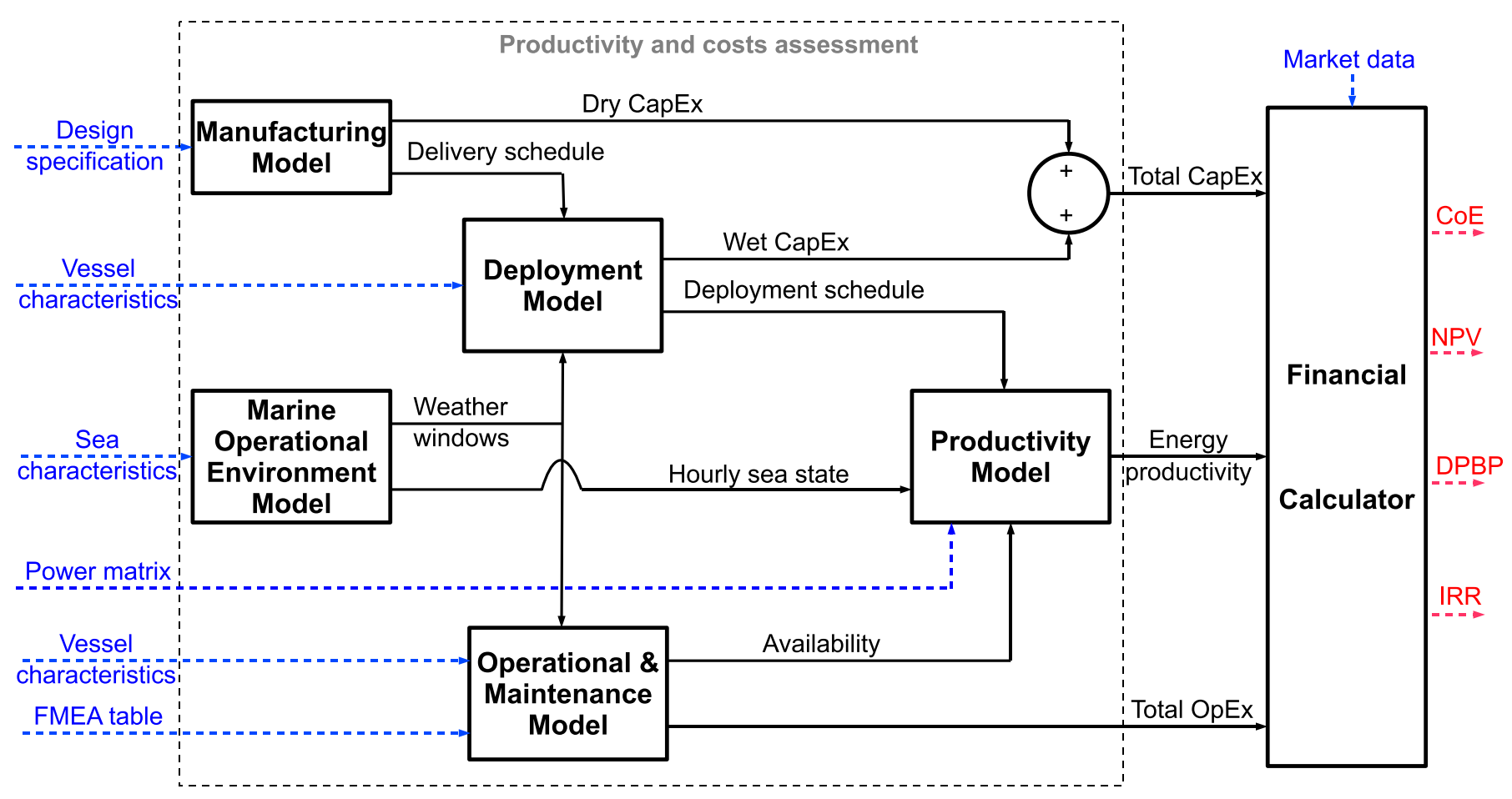

Fig. 2. Schematic of the wave farm productivity and financial calculator.

\subsection{Productivity and costs assessment}

In order to put together all the principal phases forming a large wave energy scheme, the productivity and costs assessment encompasses five core sub-models (as shown in Fig. 2) using a $1 \mathrm{~h}$ time resolution, namely:

1. A marine operational environment model,

2. A manufacturing model,

3. A deployment model,

4. An operation and maintenance (O\&M) model, and

5. A productivity model.

\subsubsection{Marine operational environment model}

The marine operational environment model builds the hourly history of the sea state over the project lifetime and determines the weather windows suitable for marine operations. From the raw wave measurement time series, a spectral analysis is computed to obtain the main hourly parameters which describe the sea state; the significant wave height, $H_{s}$, the peak period (corresponding to the maximum spectral density), $T_{p}$, and the mean wave energy period, $T_{e}$.

In offshore engineering, a weather window is a period of time where quantities such as $H_{s}, T_{p}, T_{e}$ etc..., remain at levels which permit a given set of marine operations to be performed safely. For planning management purposes, the durations, the starting time and the number of occurrences of the weather windows need to be specified [15].

Among the various factors that can impact the offshore accessibility (wave height, wind speed, wave period, tidal flow, luminosity and temperature), $H_{s}$ is one of the most common parameters used to determine weather windows [16]. In our model, a wave height threshold beyond which it becomes unreasonable to manoeuvre (denoted $H_{s}^{c}$ ) is solely used for determining the weather windows, with no dependence on the wave period.
During the energy productivity assessment, our model considers two different types of vessels: a larger one suitable for towing of the WECs and a smaller one suitable for transport of personnel for on-site inspections and repairs. Regardless of the type of marine operation (installation, repair, inspection, removal), the model defines a standard procedure for marine operations as shown in Fig. 3. The transit time between the port and the site is estimated according to the distance and the vessel speed capability.

\subsubsection{Manufacturing model}

Given the design specifications and manufacturing cost estimates, the manufacturing model provides two separate intermediate outputs: the delivery schedule for the series of WECs to make up the wave farm and the capital costs associated with the construction of each unit.

The calculation of the dry CapEx is directly related to physical parameters specified in the design specifications such as, for example:

- The type of material required for the hull structure,

- The volume of material,

- The PTO maximum stroke,

- The PTO maximum force,

- The minimum breaking load of mooring lines, and

- The maximum power rating of electrical equipment.

\subsubsection{Deployment model}

The deployment model provides the deployment schedule for the series of WECs to be connected to the grid and the capital costs associated with the complete installation of the wave farm.

In this model, the time allocated to the deployment of each unit is determined. The transit time for device towing is not only calculated according to the distance between the port and the site but also according to the towing speed specific to the vessel. Assuming an estimate of the towing resistance of the device under 


\section{Pre-processing: AUTHORIZATION}

- $\quad$ Find the first satisfactory weather window

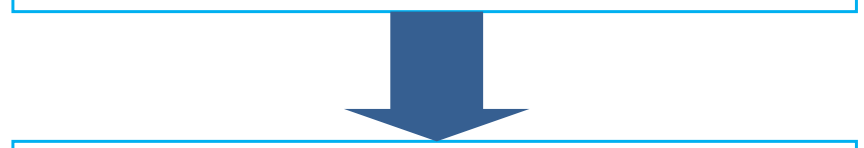

\section{Processing: OPERATION}

- Outward journey of the vessel

- Operation: Install/Remove/Inspect/Repair

- Return journey of the vessel

\section{Post-processing: UPDATE}

- $\quad$ Reduce the remaining duration and increase the starting time of the weather window used for future usage

Fig. 3. Standard marine operations procedure.

consideration is available, the towing speed for a given size/power of boat may be adjusted. In addition, the on-site installation working duration is also estimated. Adding the durations of on-site work and the transit time, we can predict the total duration for the deployment of one unit. From this stage, the deployment model engages the standard marine operation procedure, depicted in Fig. 3, and starts to look for the first suitable weather window.

A concurrent use of vessels, particularly during the deployment stage, may be required for projects comprising a large number of units. Therefore, it is possible to handle the marine operation simulations with one or several boats of each type. Our model integrates boat purchase rates and hourly renting rates to support both financing strategies. By integrating the transportation costs assessment for both financing strategies, our model attempts to measure the purchase strategy against the hiring one.

The expenses occurring during the deployment phase are aggregated under the quantity labelled "wet CapEx". An initial investment is needed to consider:

- The purchase of suitable vessels in the case of the purchase strategy,

- The implementation of the grid connection, and

- The lease and insurance for the site.

The grid connection costs are driven primarily by the length of sub-sea and land cables, as well as the maximum power capacity of the plant and the voltage level available at the shoreline [17]. Using an hourly rate estimate for the price of personnel and equipment required during the deployment of each unit, the deployment model also quantifies the man-hour costs of manoeuvring one device from shore until its connection to the grid offshore.

\subsubsection{Operation and maintenance model}

The O\&M model returns two intermediate outputs: firstly, the total operational costs associated with the maintenance activities and secondly, the farm availability for production over the lifetime, using a $1 \mathrm{~h}$ time step.

\begin{tabular}{|c|c|c|c|c|c|c|c|c|c|c|c|c|c|c|c|c|c|c|c|c|c|}
\hline & & & & & & & & & ner & $y p$ & iod & $T_{0}($ & & & & & & & & & \\
\hline & 4.75 & 5.25 & 5.75 & 6.25 & 6.75 & 7.25 & 7.75 & 8.25 & 8.75 & 9.25 & 9.75 & 10.25 & 10.75 & 11.25 & 11.75 & 12.25 & 12.75 & 13.25 & 13.75 & 14.25 & 14.75 \\
\hline 0.5 & idle & idle & idle & idle & idle & idle & idle & idle & idle & idle & idle & idle & \begin{tabular}{|l|} 
idlle \\
\end{tabular} & \begin{tabular}{|l|} 
idle \\
\end{tabular} & idle & idle & idle & idle & idle & idle & idle \\
\hline 1 & idle & 29 & 44 & 56 & 64 & 66 & 65 & 62 & 57 & 52 & 47 & 42 & 37 & 33 & 29 & 25 & 22 & 20 & 18 & 16 & 14 \\
\hline 2 & idle & 117 & 175 & 224 & 254 & 266 & 262 & 248 & 229 & 208 & 187 & 166 & 147 & 130 & 115 & 102 & 90 & 80 & 71 & 63 & 56 \\
\hline 2.5 & idle & 183 & 274 & 350 & 397 & 415 & 409 & 388 & 358 & 325 & 291 & 260 & 230 & 204 & 180 & 159 & 141 & 124 & 110 & 98 & 87 \\
\hline 3 & idle & 263 & 395 & 504 & 572 & 598 & 589 & 558 & 515 & 468 & 420 & 374 & 332 & 293 & 259 & 229 & 202 & 179 & 159 & 141 & 125 \\
\hline 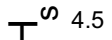 & - & - & 888 & 1133 & 1287 & 1345 & 1325 & 1256 & 1160 & 1052 & 944 & 841 & 746 & 660 & 584 & 516 & 456 & 403 & 357 & 317 & 281 \\
\hline 5 & - & - & - & 1399 & 1589 & 1660 & 1636 & 1550 & 1432 & 1299 & 1166 & 1039 & 921 & 815 & 720 & 636 & 562 & 498 & 441 & 391 & 347 \\
\hline 5.5 & - & - & - & 1693 & 1923 & 2008 & 1980 & 1876 & 1732 & 1572 & 1411 & 1257 & 1115 & 986 & 872 & 770 & 681 & 602 & 533 & 473 & 420 \\
\hline 6 & - & - & - & - & 2289 & 2390 & 2356 & 2233 & 2061 & 1871 & 1679 & 1496 & 1327 & 1174 & 1037 & 916 & 810 & 716 & 635 & 563 & 500 \\
\hline 6.5 & - & - & - & - & 2686 & 2805 & 2765 & 2620 & 2419 & 2196 & 1970 & 1756 & 1557 & 1378 & 1218 & 1076 & 951 & 841 & 745 & 661 & 587 \\
\hline 7 & - & - & - & - & - & 3253 & 3207 & 3039 & 2806 & 2547 & 2285 & 2036 & 1806 & 1598 & 1412 & 1247 & 1102 & 975 & 864 & 766 & 681 \\
\hline 7.5 & - & - & - & - & - & 3500 & 3500 & 3488 & 3221 & 2923 & 2623 & 2337 & 2073 & 1834 & 1621 & 1432 & 1266 & 1119 & 991 & 879 & 781 \\
\hline 10 & - & - & - & - & - & - & - & 3500 & 3500 & 3500 & 3500 & 3500 & 3500 & 3261 & 2882 & 2546 & 2250 & 1990 & 1763 & 1563 & 1389 \\
\hline 10.5 & - & - & - & - & - & - & - & - & 3500 & 3500 & 3500 & 3500 & 3500 & 3500 & 3177 & 2807 & 2480 & 2194 & 1943 & 1724 & 1532 \\
\hline 11 & - & - & - & - & - & - & - & - & 3500 & 3500 & 3500 & 3500 & 3500 & 3500 & 3487 & 3080 & 2722 & 2408 & 2133 & 1892 & 1681 \\
\hline 11.5 & - & - & - & - & - & - & - & - & 3500 & 3500 & 3500 & 3500 & 3500 & 3500 & 3500 & 3367 & 2975 & 2632 & 2331 & 2068 & 1837 \\
\hline 12 & - & - & - & - & - & - & - & - & - & 3500 & 3500 & 3500 & 3500 & 3500 & 3500 & 3500 & 3240 & 2866 & 2538 & 2251 & 2001 \\
\hline 12.5 & - & - & - & - & - & - & - & - & - & 3500 & 3500 & 3500 & 3500 & 3500 & 3500 & 3500 & 3500 & 3109 & 2754 & 2443 & 2171 \\
\hline 13 & - & - & - & - & - & - & - & - & - & - & 3500 & 3500 & 3500 & 3500 & 3500 & 3500 & 3500 & 3363 & 2979 & 2642 & 2348 \\
\hline 13.5 & - & - & - & - & - & - & - & - & - & - & 3500 & 3500 & 3500 & 3500 & 3500 & 3500 & 3500 & 3500 & 3212 & 2849 & 2532 \\
\hline 14 & - & - & - & - & - & - & - & - & - & - & 3500 & 3500 & 3500 & 3500 & 3500 & 3500 & 3500 & 3500 & 3455 & 3064 & 2723 \\
\hline 14.5 & - & - & - & - & - & - & - & - & - & - & - & 3500 & 3500 & 3500 & 3500 & 3500 & 3500 & 3500 & 3500 & 3287 & 2921 \\
\hline
\end{tabular}

Fig. 4. Power matrix scatter plot of a generic axisymetric device, numbers are expressed in kW. 
Currently, the O\&M model includes two scheduled maintenance operations, namely the on-site service and the mid-life refit. Assuming servicing a WEC on-site is possible for repair and/or inspection, the routine on-site visits are performed at a chosen frequency (typically annual or bi-annual), the overhaul activity occurs only once after the operational life of the device reaches half of the WEC lifetime assumed. The mid-life refit involves the towing of each unit for onshore maintenance and therefore allows major component replacement.

Unscheduled maintenance is also simulated, based on a stochastic approach. Breakdown events are assumed to occur randomly according to the likely frequency rates of failure given the FMEA table. Depending on the nature of the failure and the availability of both the repair equipment and teams, the type of operation and the recovery time is adjusted.

The expenses associated with every maintenance operation are assessed through the estimation of hourly rates, the cost of parts and the cost of vessel hire. In the end, the O\&M model gives the history of the maintenance activities for each unit along with the impact on both the availability for production and the O\&M costs.

\subsubsection{Productivity model}

The productivity model generates the hourly wave farm power production over the lifetime, by combining the power matrix, the availability and the wave measurements. For each hour, the energy production is given by the cell corresponding to the couple $\left(H_{s}, T_{e}\right)$ defining the sea state in the power matrix. In [18], a methodology for quantifying the effects of the farm lay-out on the production and cost assessment is proposed. However, for the moment, our model neglects constructive and destructive interferences that occur between devices in an array lay-out.

\subsection{Financial calculator}

Combining the outputs provided by the productivity and cost assessment, the financial calculator gives an economic value measure of a wave energy scheme. While the productivity and cost assessment requires a $1 \mathrm{~h}$ time step, the financial calculator is executed on a yearly basis.

\subsubsection{Market data}

The financial calculations of a project are subject to the established financial and political policies governing the local market where the project is undertaken. As an emerging industry, the wave energy sector is prone to evolving financial rules and policies. In the $\mathrm{UK}$, the ROC is issued for eligible operators supplying electricity to the national territory with green power for each MWh they produce. The nature and different aspects of the ROC are regularly being reviewed reflecting the evolving character of the renewable industry [9].

In Ireland, a similar renewable energy feed-in-tariff (REFIT) programme is also currently under revision [19]. The financial calculator can also be adapted to other price support mechanisms e.g. renewable energy production tax credit, in the USA. For each kWh of energy produced, the revenue obtained (denoted Rev in Eq. (1)) is given by the tariff secured by a REFIT-type program. At the end of each year, the total revenue generated is directly formulated. Since the period of time where the support price mechanism applies may differ from the total duration of a project, the financial calculator considers an average retail price of energy beyond the tariff duration of the price support mechanism until the end of last year of the project lifetime.

More traditional financial assumptions such as the tax rates are used in alignment with financial practice in related industries (offshore, renewable energy). For instance, the model has the capability to simulate corporate taxes (including feed-in-tariff reductions) and the annual income tax deductions due to the depreciation of the infrastructure.

\subsubsection{Discounted cash-flow algorithm}

The discounted cash-flow (DCF) technique tries to work out the value of a project today, based on projections of how much money it is going to make in the future. Hence, the DCF analysis projects the amount of money that would circulate within the company or the project with respect to the CapEx, the OpEx, the revenue and a discount rate.

Koller et al. [20] examine, with meticulous care, different existing approaches for the DCF method within various market environmental conditions. To arrive at the yearly DCF, the standard procedure is to calculate, firstly, the annual revenue and secondly, the annual taxes according to the financial environment (respectively denoted $\operatorname{Rev}(\mathrm{y})$ and Taxes(y) in Eq. (1)). Analytically, the DCF at each year $\mathrm{y}$, as implemented in our model, is given by the following expression:

$$
\begin{aligned}
\operatorname{DCF}(y) & =\frac{\operatorname{FCF}(y)}{\left(1+\frac{R_{d}}{100}\right)^{y}} \\
& =\frac{\operatorname{Rev}(y)-\operatorname{OpEx}(y)-\operatorname{CapEx}(y)-\operatorname{Taxes}(y)}{\left(1+\frac{R_{d}}{100}\right)^{y}}
\end{aligned}
$$

where $R_{d}$ is the discount rate.

\subsubsection{Financial indicators}

For a given project lifetime, $Y$, our model uses the present value (PV) approach to calculate the LCoE:

$\mathrm{LCoE}=\frac{\mathrm{PV}(\text { CapEx })+\mathrm{PV}(\mathrm{OpEx})}{\mathrm{PV}(\mathrm{EP})}$

where EP is the energy production in kWh and the PV of a cashflow $\mathrm{CF}$ is defined as:

$$
\mathrm{PV}(\mathrm{CF})=\sum_{y=y_{0}}^{Y} \frac{\mathrm{CF}(y)}{\left(1+\frac{R_{d}}{100}\right)^{y}}
$$

and $y_{0}$ is the first non-zero value year of the cash-flow CF.

The NPV is obtained by adding all the discounted cash-flows over the lifetime as demonstrated in Eq. (4). For a project to be profitable, a strictly positive NPV at the end of the project is a necessary condition.

$\mathrm{NPV}=\sum_{y=0}^{Y} \frac{\mathrm{FCF}(y)}{\left(1+\frac{R_{d}}{100}\right)^{y}}=\sum_{y=0}^{Y} \operatorname{DCF}(y)$

In addition, the IRR is commonly used, along with the NPV, to assess the desirability of a project. The higher the IRR is above the discount rate a project is expected to have, the more desirable it is to undertake the project. By definition, the IRR is the percentage which corresponds to the discount rate used in capital budgeting that makes the NPV of all cash flows from a particular project equal to zero and can be conveniently defined as the solution of the following equation.

$\sum_{y=0}^{Y} \frac{\mathrm{FCF}(y)}{\left(1+\frac{\operatorname{IRR}}{100}\right)^{y}}=0$ 
Table 1

Failure modes and effect analysis table.

\begin{tabular}{|c|c|c|c|c|c|c|c|}
\hline Component name & $\begin{array}{l}\text { Quantity in } \\
\text { design }\end{array}$ & $\begin{array}{l}\text { Probability of } \\
\text { failure (per year) }\end{array}$ & $\begin{array}{l}\text { Consequence of } \\
\text { failure (\% power loss) }\end{array}$ & $\begin{array}{l}\text { Cost of parts } \\
\text { (in } € \text { ) }\end{array}$ & $\begin{array}{l}\text { Man hours of } \\
\text { repair (in hours) }\end{array}$ & $\begin{array}{l}\text { Manpower } \\
\text { cost (in } € / \text { hour) }\end{array}$ & $\begin{array}{l}\text { Repair on-site } \\
\text { onshore }\end{array}$ \\
\hline Hull structure & 2 & 0.0066 & $100 \%$ & 50,000 & 72 & 1500 & Onshore \\
\hline Bearing pads & 12 & 0.002 & $100 \%$ & 2000 & 10 & 500 & Onshore \\
\hline Motor & 1 & 0.005 & $100 \%$ & 25,000 & 48 & 500 & Onshore \\
\hline Dynamic riser & 1 & 0.00125 & $50 \%$ & 10,000 & 20 & 1000 & On-site \\
\hline Mooring line & 4 & 0.0013 & $100 \%$ & 20,000 & 100 & 1500 & On-site \\
\hline Generic component & 120 & 0.005 & $100 \%$ & 2500 & 12 & 500 & On-site \\
\hline
\end{tabular}

Finally, the DPBP gives the minimum number of years it takes to recover from undertaking the initial investment including the cost of capital. The DPBP satisfies Eq. (6).

$\sum_{y=0}^{\mathrm{DPBP}} \mathrm{DCF}(y) \geq 0$

\section{Sample results}

In this Section, we simulate a wave farm of 100 units, located off the West Coast of Ireland at the Atlantic Marine Energy Test Site, AMETS. The sea characteristic measurements utilized were provided by the Irish Marine Institute in the form of observations collected at Belmullet (Latitude: +54.266 Longitude: -10.143 ), by means of a waverider data buoy. The wave readings contain raw sea surface elevation time series at a sampling frequency of $1.28 \mathrm{~Hz}$. The data were recorded in the period from December 2009 to January 2011.

We consider an axisymetric oscillating 2-body device exploiting its relative motion in heave. In Fig. 4, the power matrix of the device indicates a maximum power rating of 3.5 MW. The grey cells on the bottom left corner in the scatter plot of the power matrix correspond to sea-states beyond the theoretical maximum wave steepness $(1 / 7)$ and hence are very unlikely to occur in deep water conditions [21]. For extreme sea-states with $H_{s}$ larger than $14.5 \mathrm{~m}$ and/or $T_{e} 14.75 \mathrm{~s}$, one can approximate the power rating of the device by the nearest cell defined in Fig. 4.

We assume a device lifetime of 20 years with on-site visits to the WECs for maintenance performed on a yearly basis and an overhaul activity operated after the mid-life of each unit. In order to test a wide variety of breakdown events, a generic FMEA table, as shown in Table 1, was implemented in this example. The numbers in Table 1 were determined using information relative to other industries and hence do not represent a particular WEC concept. The purchase of one boat, suitable for on-site service, and another suitable for towing services, is accounted for.

In this sample example, the Irish financial environment is chosen which implies a corporate tax rate of $12.5 \%$ and a feed-intariff of $0.22 € / \mathrm{kWh}$ [19]. For comparison, we realise the same assessment, assuming a level of 5 ROCs price support mechanism is available. In [9], the value of a ROC is discussed and we assume, in our example a value, of $50 £ / M W h$ which is close to the average of the value of a ROC over the period 2005-6 to 2008-9. Finally, we use a discount rate of $10 \%$, in the range for wave and tidal energy projects recommended by Carbon Trust [6].

\subsection{Productivity and economic assessment}

\subsubsection{Productivity assessment results}

As stated in Section 2.2.1, starting from the raw data measurements, the marine operational environment model builds the hourly history of the sea state. In Fig. 5, we plot the variation of both
$H_{s}$ and $T_{e}$, over the year 2010 at Belmullet, using a $1 \mathrm{~h}$ time step. One can appreciate the seasonality reflected by a more energetic sea during the winter (i.e. $H_{s}$ and $T_{e}$ are higher). The local peaks appearing, such as those in September and November, can be explained by the presence of storms.

Fig. 6 presents a study of the weather windows at Belmullet in 2010 where the underlying wave data is the same as that for Fig. 5. In Fig. 6(a), the monthly percentage of accessibility is shown for three different significant wave height criteria for access $\left(H_{s}^{c}\right)$. In Fig. 6(b), one can see the number of weather windows per year, classified in duration order, considering the same three $H_{s}^{c}$. If a boat with a wave height threshold limited to $1 \mathrm{~m}$ was to be chosen at this location, no access during half of the year should be anticipated and, hence, the marine operations could only be executed in summer and within relatively short periods of time.

Fig. 7 displays the number of devices available over the project lifetime, assuming a $H_{s}^{c}$ of $1.5 \mathrm{~m}$. The graph identifies three important phases: the deployment, the mid-life refit and the recovery. One can note that the variability of the availability during the operational life of the farm is dominated by the failure. During the mid-life refit period, we notice that the availability never reaches $100 \%$, as expected.

The productivity assessment can assist different aspects of the management of a wave energy project. In particular, a histogram representing the percentage of boat usage during the deployment phase, the operational life and the recovery of the units, assuming one on-site inspection vessel and one towing vessel, is given in Fig. 8. The percentage of boat usage is derived from the ratio of actual boat utilization time over the total duration of a given period of time. For a project of 100 units and 20 years of device lifetime located at Belmullet, and three $H_{s}^{c}$ values ranging from $1 \mathrm{~m}$ to $2 \mathrm{~m}$, one can note significant improvements in terms of actual boat usage with an increase of $H_{s}^{c}$. In other words, Fig. 8 indicates that less restrictive conditions for marine operations accessibility leads to a reduction of the boat waiting time at the harbour. The remainder of the study will adopt a $H_{s}^{c}$ value of $1.5 \mathrm{~m}$.

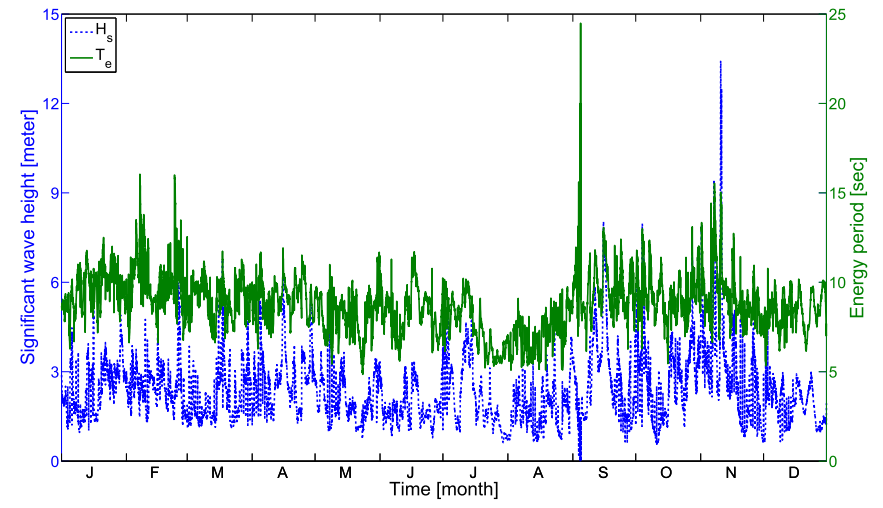

Fig. 5. Significant wave height and energy period variations at Belmullet in 2010 . 

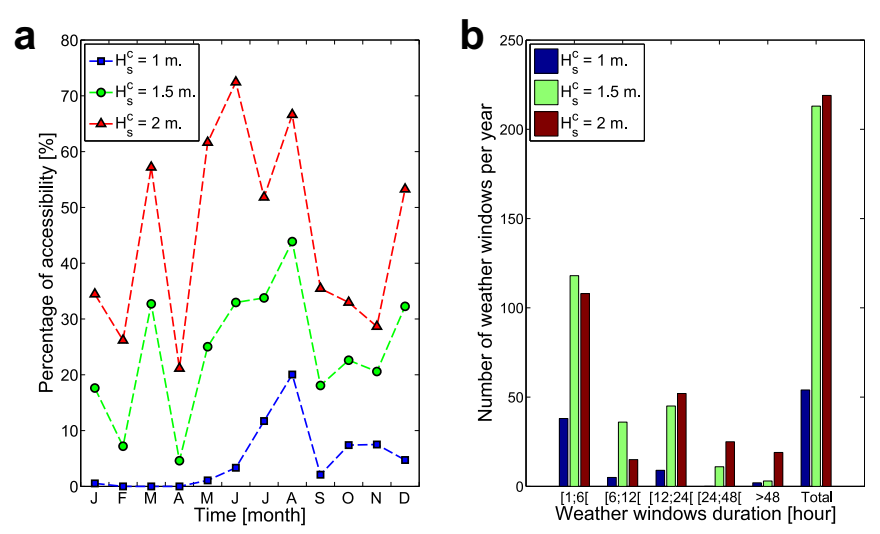

Fig. 6. Accessibility and weather windows durations at Belmullet in 2010 .

\subsubsection{Economic assessment results}

In parallel to the energy productivity assessment, the costs occurring at each phase of the lifecycle are estimated. Initially, the dry CapEx quantification addresses the costs of manufacturing. In Fig. 9, we depict the breakdown of the manufacturing costs into a number of categories. While the main hull structure realization occupies a significant share of the costs, the mechanical, hydraulic, electrical and electronic equipment (i.e. PTO, instrumentation, control and on-board electrical equipment) that are fitted to the device also contribute significantly to the costs of a unit. The mooring system cost accounts for the second largest share of the total price of a unit.

In the wet CapEx calculation, the grid connection costs are estimated using the electrical inter-array network proposed in [22]. The pie chart in Fig. 10 gives the share of the drivers of the grid connection costs which is dominated by the submarine cable component.

Three maintenance activities contribute to the OpEx, namely: the on-site service, the overhaul and the failures. In Table 2, we specify the outcome of each activity for the maintenance strategy chosen in this example.

An illustration of the cash-flow economics during the operational stage of the project is shown in Fig. 11, assuming a tariff of $0.22 € / \mathrm{kWh}$. From left to right, 4 vertical bars in each year represent (respectively) the revenue, the OpEx, the free cash-flow and the discounted cash-flow for each year of the operational life of the project. Between years 11 and 13, one can notice larger operational costs appearing due to the mid-life refit. The last year of the project indicates a relatively large amount of positive free cash-flow compared to the amount of revenue generated, which actually reflects the salvage value of the asset at the end of its useful life. The

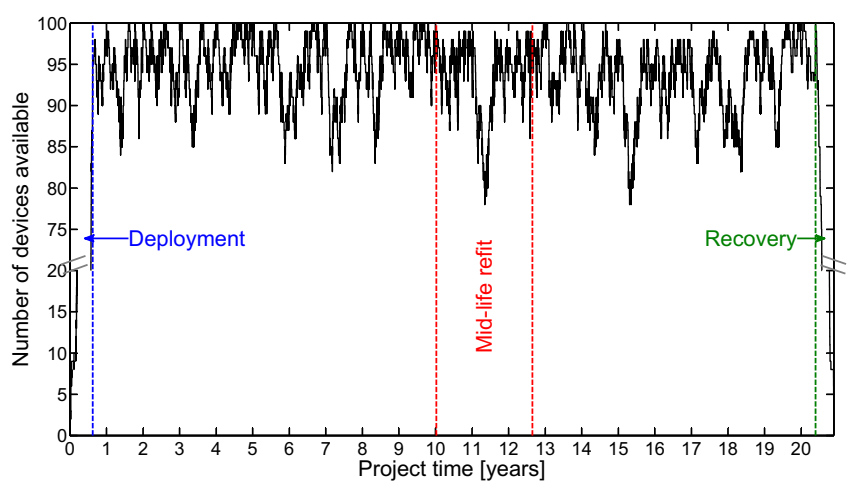

Fig. 7. Farm availability at Belmullet for 100 units.

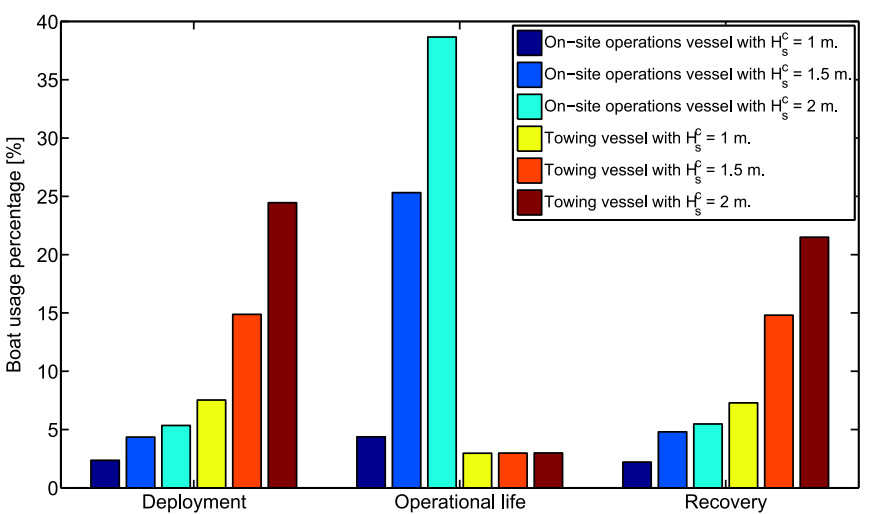

Fig. 8. Percentage of boat usage assuming one boat of each type with sequential use at Belmullet for 100 units.

final value of the four financial metrics introduced in Section 1 can be found in Table 3, for the two different price support mechanisms, namely the REFIT and the ROC.

\subsection{Sensitivity analysis}

Due to the lack of available feedback data from operators, which would serve the validation of all these estimates for the wave energy industry, our model relies on quotations obtained after consulting potential collaborators through the supply chain and existing information in the literature (particularly in the offshore engineering industry). As a result, the absolute final financial metrics are subject to the degree of confidence underlying these quotations. In order to capture a greater level of understanding of the results, the impact of the variation of the parameter estimates on these final values needs to be assessed. The following sensitivity analysis serves this purpose.

We calculate the variation and the sensitivity of the NPV and the IRR to different model inputs. For each plot containing stochastic data, a second order polynomial curve fitting of the sensitivity is included to visualize the general trend of the sensitivity.

\subsubsection{Impact of the number of units}

In order to assess the influence of the number of units using our model, we simulate a project using 1-400 units, adding one unit at each iteration. All the underlying inputs and data used are the same as for the previous case study example in Section 3.1.

The normalised variation of the average availability per unit, CapEx per unit and OpEx per unit is given in Fig. 12. The CapEx per

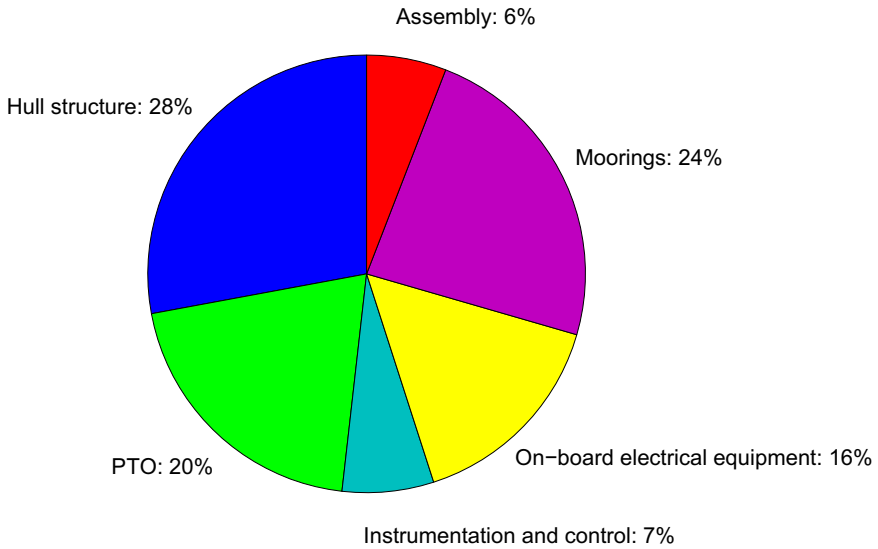

Fig. 9. Manufacturing costs breakdown of the device. 


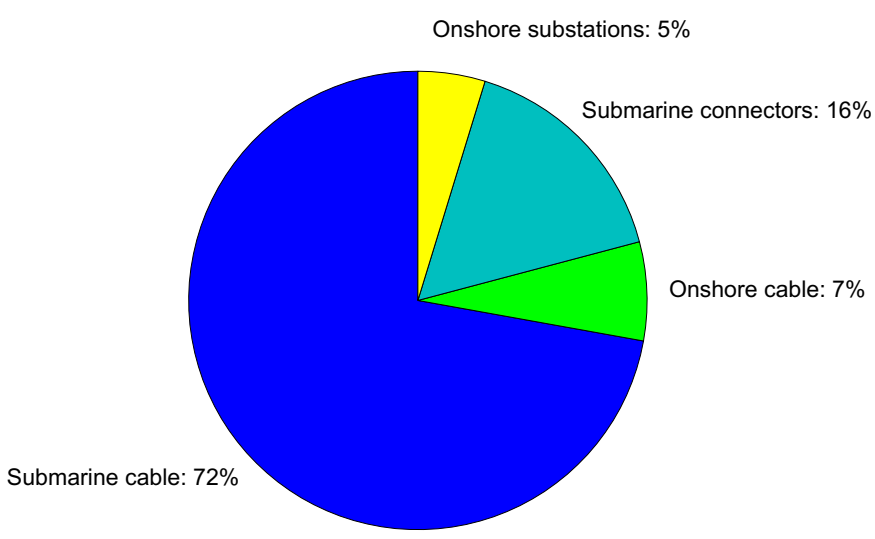

Fig. 10. Grid connection costs breakdown at Belmullet.

Table 2

Outcome of the maintenance activities.

\begin{tabular}{lllc}
\hline $\begin{array}{l}\text { Maintenance } \\
\text { activity name }\end{array}$ & $\begin{array}{l}\text { Number of marine } \\
\text { operations }\end{array}$ & $\begin{array}{l}\text { Total duration } \\
\text { (Hours) }\end{array}$ & $\begin{array}{l}\text { Operational } \\
\text { costs (M€) }\end{array}$ \\
\hline On-site service & 1900 & 17,860 & 4.0 \\
Overhaul & 100 & 15,070 & 7.9 \\
Failures & 1317 & 67,289 & 28.2 \\
\hline
\end{tabular}

unit decays and rapidly tends towards a limit value which suggests that the large initial front investment, independent of the number of units included in the CapEx quantification (for instance the purchase of the boats), is more suitable for a large wave farm. The average percentage of availability decreases monotonically as the number of units increases. One can note a sharp drop in the OpEx per unit which may be explained by the saturation of the use of the summer weather windows for the deployment phase. This saturation would lead to the extension of the deployment duration over the next year, after a long period of unsuitable weather conditions for marine operation accessibility during the winter. Furthermore, such saturation would possibly induce the denial of some marine operations due to the unavailability of the vessels required to operate them and, as a consequence, diminish the availability and the OpEx per unit.

In addition, the variation of the NPV and IRR along with their corresponding sensitivity numbers are plotted against the number of units, for both the REFIT and the 5 ROCs scheme, in Fig. 13. Under the 5 ROCs scheme, the NPV attains a maximum value for about 120 units (Fig. 13(b)) while the NPV decreases and remains always negative in the case of the REFIT (Fig. 13(a)). The asymptotical

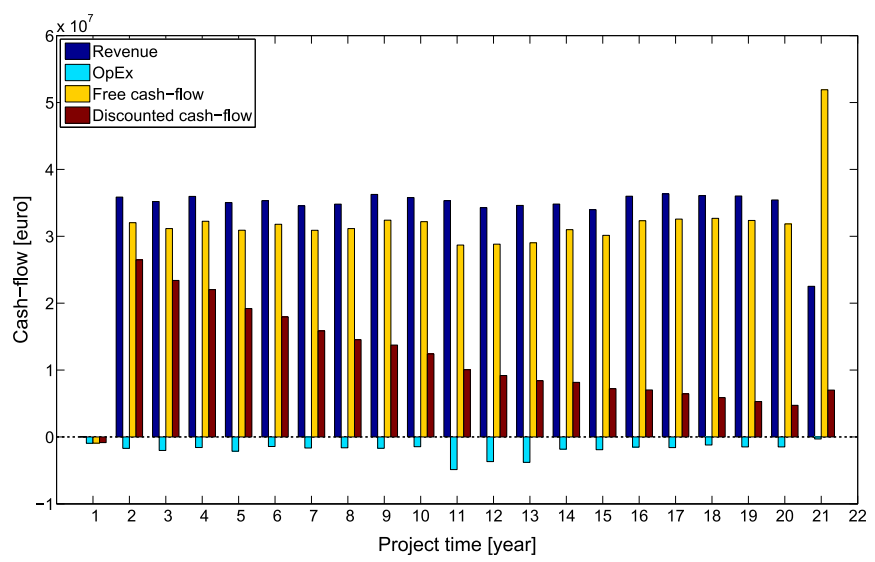

Fig. 11. Operational cash-flows at Belmullet for 100 units.
Table 3

Value of the financial indicators.

\begin{tabular}{lll}
\hline Indicator & REFIT $(0.22 € / \mathrm{kWh})$ & 5 ROCs $(\approx 0.29 € / \mathrm{kWh})$ \\
\hline LCoE & $0.213 € / \mathrm{kWh}$ & $0.215 € / \mathrm{kWh}$ \\
NPV & $-33.1 \mathrm{M} €$ & $24.9 \mathrm{M} €$ \\
DPBP & $>$ project lifetime & 18 years \\
IRR & $8.2 \%$ & $11.3 \%$ \\
\hline
\end{tabular}

behaviour of the variation and the sensitivity of IRR with the number of units in both support price mechanisms (Fig. 13(c) and (d)) seems to suggest that very large wave farms (typically over 150 units) do not lead to more profitable projects. One of the reason for that is the lack of number of boats to service the wave farm when coping with a large number of units.

\subsubsection{Impact of the duration estimates}

For each marine operation, our model assumes a fixed duration. It is clear that the durations of installation, repair and removal, as well as the transit time between the port and the site, directly affect the availability. Using the case study presented in Section 3.1 as a reference, we investigate the influence of a variation in all these durations for marine operation from $-50 \%$ lower than up to $+50 \%$ greater than the reference duration.

Fig. 14 corroborates the prediction of lower economic performance for wave energy projects involving longer marine operations. However, the overall sensitivity and the range of variation of the NPV and the IRR with the duration estimates are less significant than the number of units. For instance, the scale of the sensitivity of NPV to the duration estimates in both the REFIT and ROCs cases (Fig. 14(a) and (b)) is about 100 times smaller than to the number of units in Fig. 13(a) and (b). In the same way as the OpEx per unit in Figs. 12 and 13 presents some sharp drops in the variation of NPV and IRR possibly resulting from the phenomenon of saturation of the resource available (vessel and weather windows) to deal with longer marine operations.

\subsubsection{Impact of the cost estimates}

Similarly to the relationship between the duration estimates and the availability, numerous cost estimates, used in our model, affect the expenditure quantification. Following the same principle as for the duration estimates, we vary simultaneously all the cost estimates from $-50 \%$ to $+50 \%$ of their reference value. The cost estimates include all the hourly rates for marine operations and the rate of materials and equipment.

In comparison to Figs. 14 and 15 shows that the sensitivity of the economic performance to the cost estimates is significantly greater

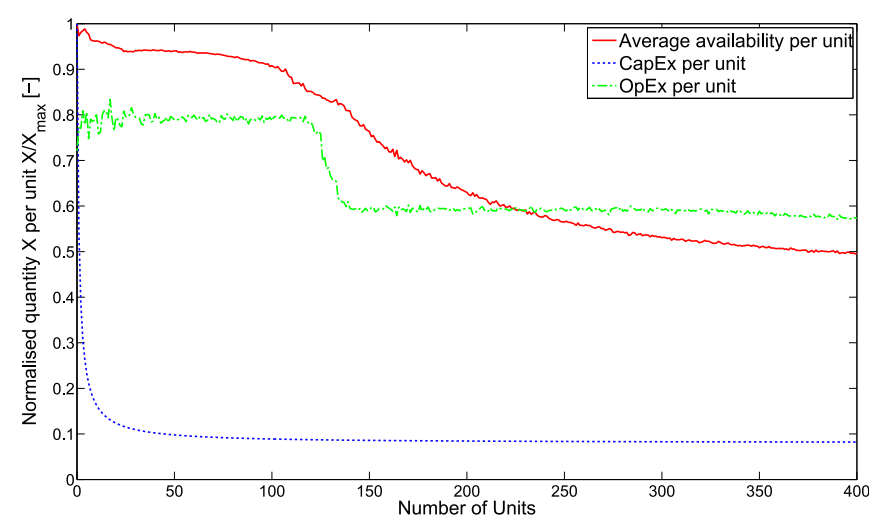

Fig. 12. Variation of the normalised average availability per unit, CapEx per unit, OpEx per unit and annual energy productivity per unit with the number of units. 

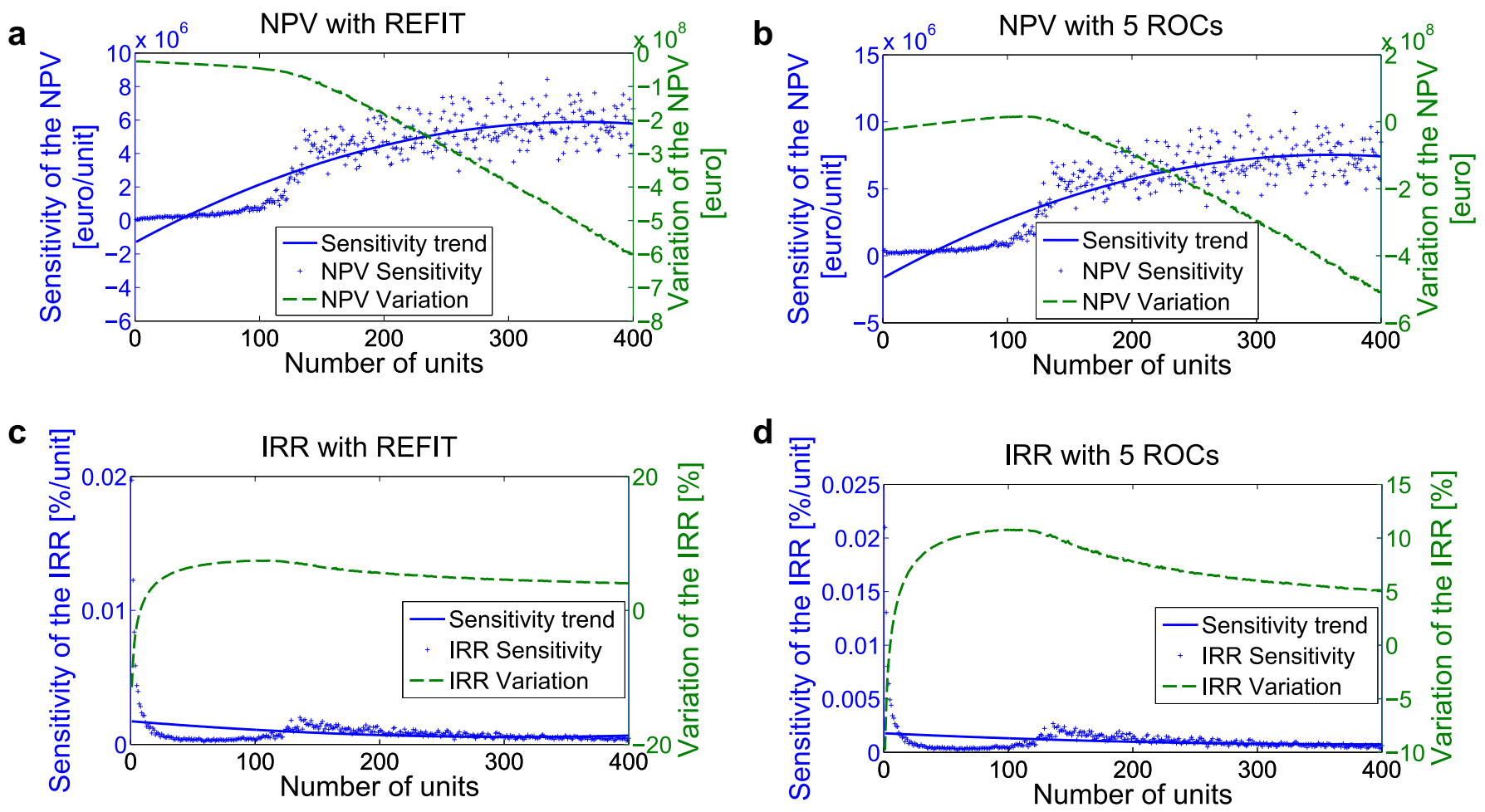

Fig. 13. Variation and sensitivity of the NPV and the IRR with the number of units for the REFIT and 5 ROCs.

than to the duration estimates. In particular, one can note that if a project developer achieves a reduction of $50 \%$ in all the cost estimates, the NPV would be improved by about $100 \mathrm{M} €$ and the IRR by about $7 \%$. Subsequently, from a business perspective, it would be preferable to allocate more resources in achieving reductions of the cost estimates over reductions of the duration estimates.

\subsubsection{Impact of the tariff}

The evolving character of the tariff, which each $\mathrm{kW}$ h produced by a WEC attracts, motivates a further sensitivity study. As a result, Fig. 16 presents the variation and sensitivity of both the NPV and the IRR with the tariff. The level of tariff offered by the REFIT and the 5 ROCs are annotated with vertical lines. a

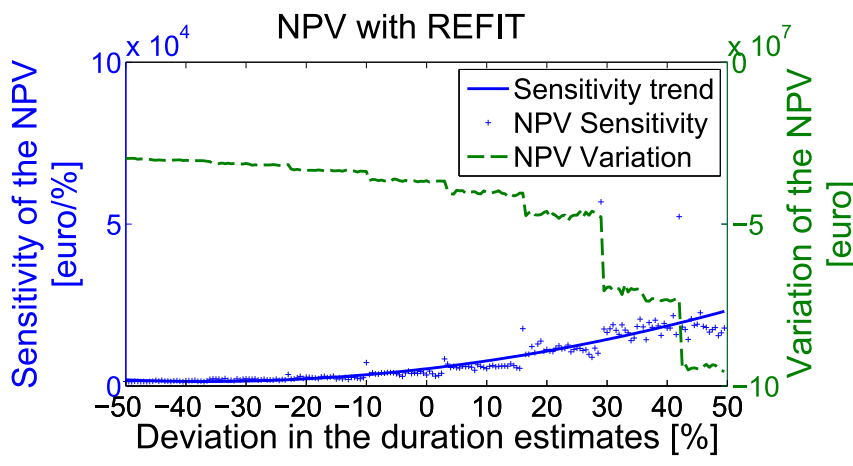

C

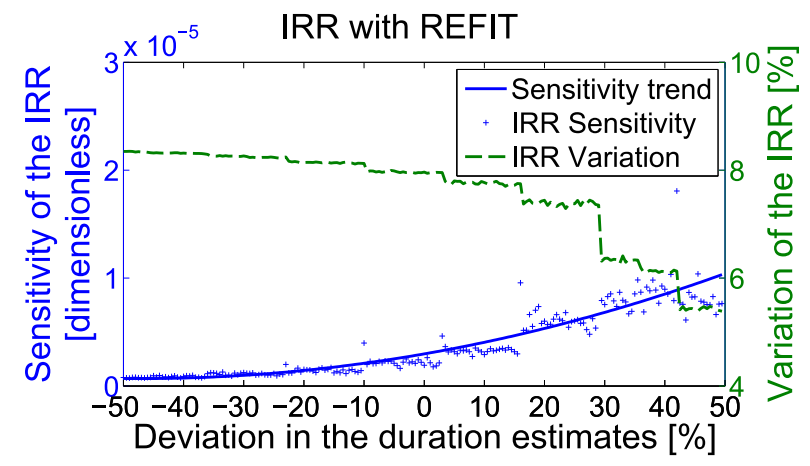

b

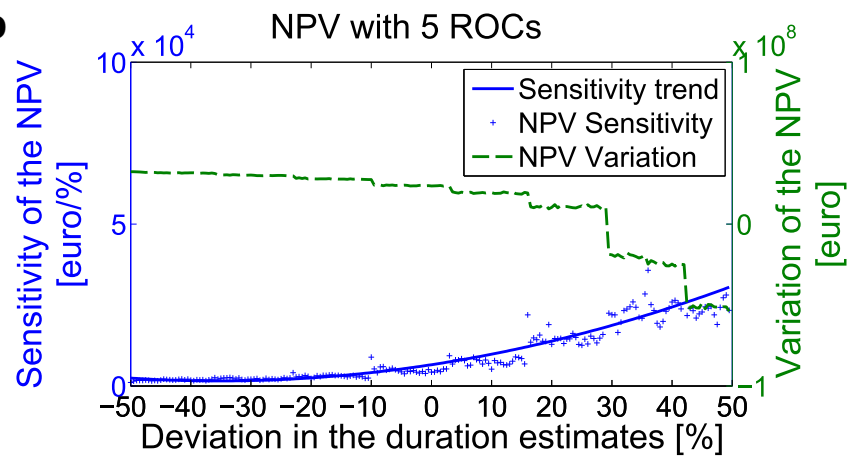

d

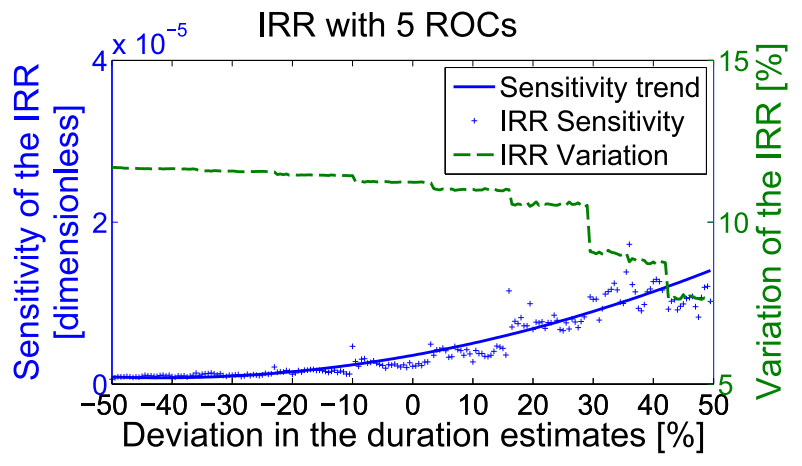

Fig. 14. Variation and sensitivity of the NPV and the IRR with the duration estimates for the REFIT and 5 ROCs. 
a
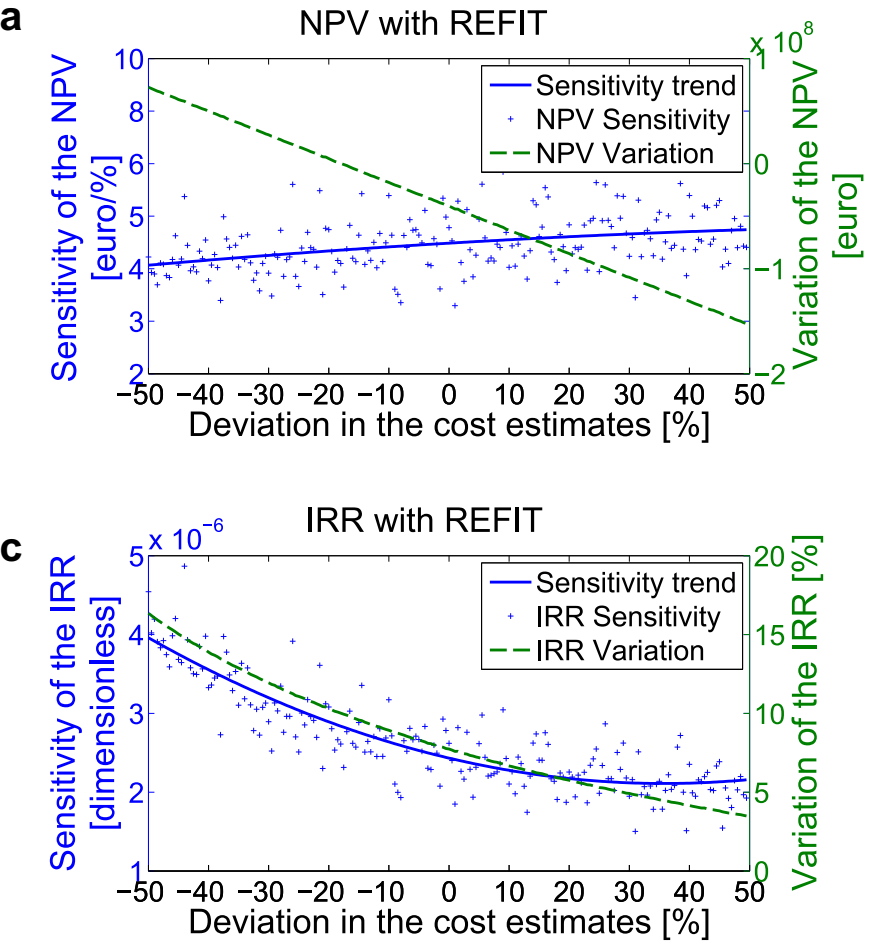

b
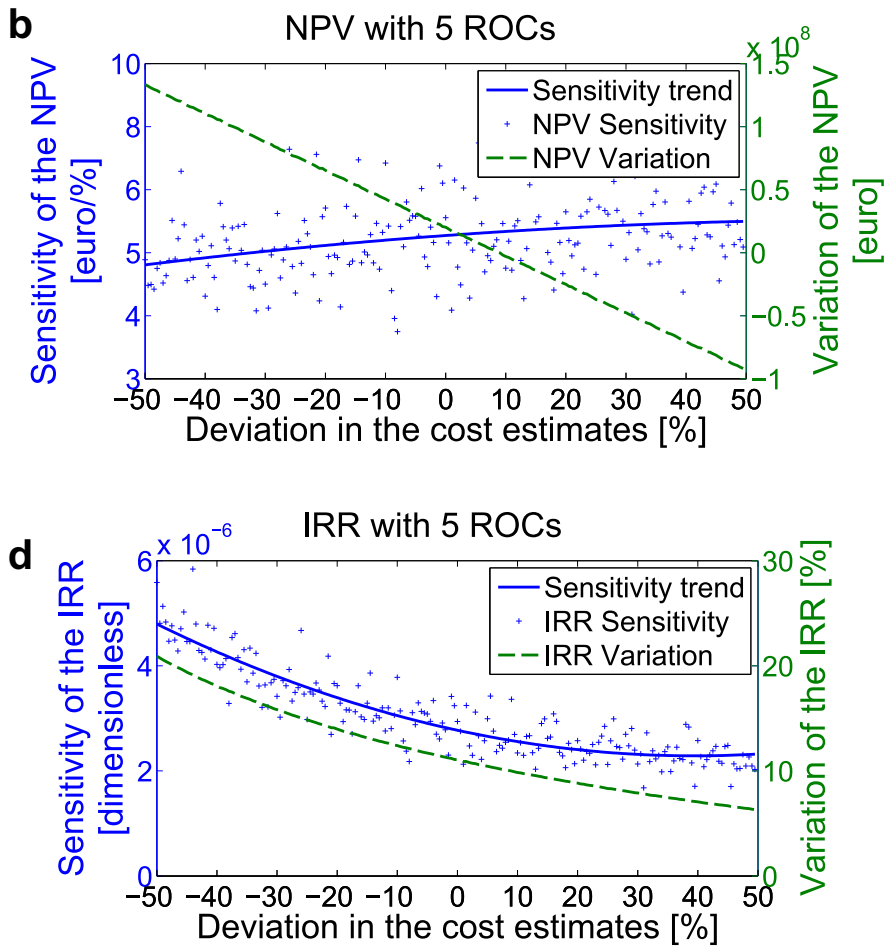

Fig. 15. Variation and sensitivity of the NPV and the IRR with the cost estimates for the REFIT and 5 ROCs.
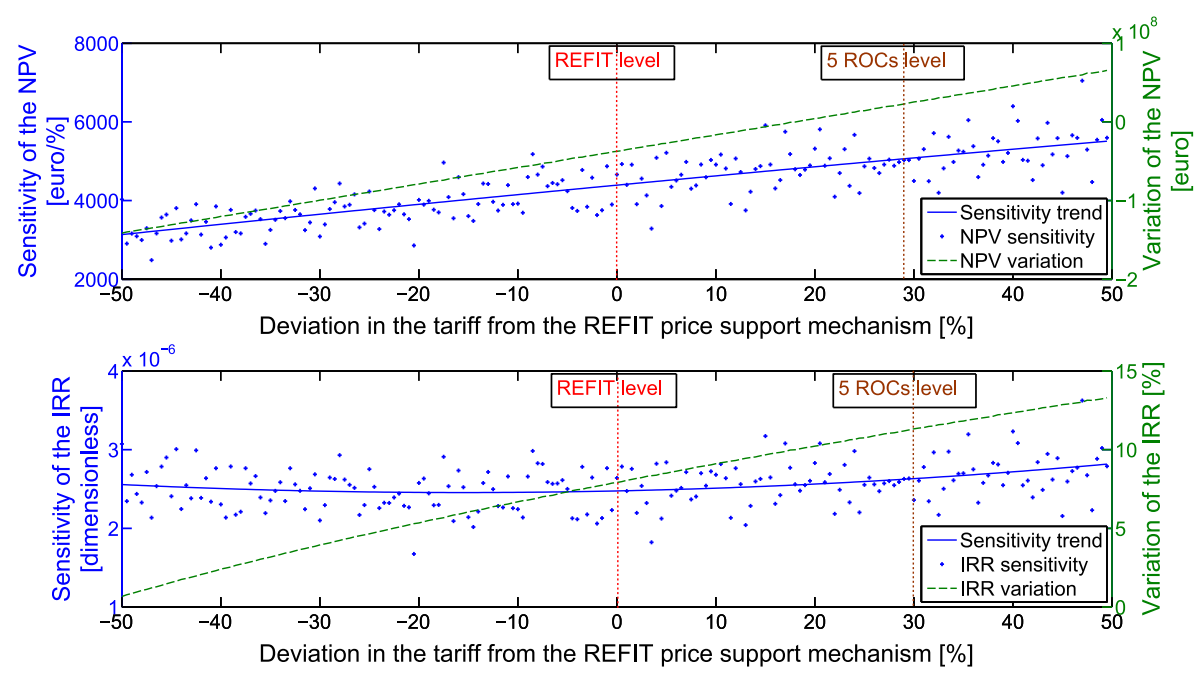

Fig. 16. Variation and sensitivity of the NPV and the IRR with the tariff.

The tariff has as significant impact on the overall economic performance as the costs estimates. For example, a tariff $50 \%$ greater than $0.22 € / \mathrm{kWh}$ (the REFIT level of support assumed in this paper) would potentially give an IRR of $13.2 \%$ compared to $8.2 \%$ for the reference case, which is significant, from an investor perspective.

\section{Conclusion}

In this paper, a tool for productivity and economic assessment is presented and illustrated with a sample case study involving the deployment of 100 WEC units off the West Coast of Ireland. The use of operational simulations for the assessment of the energy productivity are tested for a variety of maintenance activities using a standard methodology for every type of marine operation involved. The hourly quantification of the device availability and operational costs is depicted and can offer guidelines for the management of a full scale wave energy plant. Four financial metrics, including the NPV, IRR, LCoE and DPBP are also calculated, which demonstrate the capability of combining operational simulations and financial calculations to provide a wide range of economic performance indicators, necessary to the evaluation of the profitability of a wave farm.

By performing a sensitivity analysis of different inputs of the assessment on the economic value, we show that it is possible to identify the areas of a WEC technology that are of most influence on the economic performance. As a result, a developer could optimise the orientation of the allocation of development resources for 
a particular WEC technology, based on an economic argument. Each of these, in turn, serves the purpose of achieving commercial wave energy application by accelerating the definition of an attractive and competitive project plan for prospective investors.

In time, as the wave energy industry matures, a dynamic usage of such a tool for economic performance assessment is indispensable to adjust the quantification of the costs and the market environmental assumptions. Indeed, the model developed in this paper must be constantly updated as operational experience is gained in order to refine and validate its estimates. Considering the low level of maturity of the wave energy industry, it is difficult to obtain estimates for the design costs of a WEC technology and, therefore, the assessment presented here ignores them. The time and the manpower costs during the manufacturing phase are also ignored due to the almost complete lack of information relevant to the requirements for manufacturing a WEC. In the future, the design costs as well as manpower manufacturing costs will need to be added to the other costs featured in the assessment presented here.

In this paper, the power matrix has been used to evaluate the power output of the WECs for varying sea conditions, based on specification of the significant wave height, $H_{S}$ and the wave energy period $T_{e}$. However, we note that this type of power calculation can be a little misleading for resonant WECs, since they are sensitive to the particular sea power spectrum and various spectral shapes can have identical $H_{s}$ and $T_{e}$ values [23]. In particular, some seas may have little spectral power at the resonant frequency of the converter. Nevertheless, the use of a power matrix provides a computationally simple method for power output evaluation compared to a full time-domain simulation, with an error not exceeding that for the financial side calculations.

\section{Acknowledgements}

The financial support of Enterprise Ireland and Wavebob Ltd, under project IP/2009/0024 is gratefully acknowledged. In addition, the authors wish to express their acknowledgements to the Irish Marine Institute for providing real sea observations.

\section{References}

[1] Clement A, McCullen P, Falcao A, Fiorentino A, Gardner F, Hammarlund K, et al. Wave energy in Europe: current status and perspectives. Renewable and Sustainable Energy Reviews 2002;6:405-31.

[2] Atkins Oil \& Gas Engineering Ltd. A parametric costing model for wave energy technology, tech. rep. ETSU report number wv-1685. The UK Department of Trade and Industry and the Energy Technology Support Unit (ETSU); 1992.
[3] Thorpe TW. A review of wave energy, tech. rep. ETSU report number R-72. The UK Department of Trade and Industry and the Energy Technology Support Unit (ETSU); December 1992.

[4] Thorpe TW. A brief review of wave energy, tech. rep. ETSU report number R-120. The UK Department of Trade and Industry and the Energy Technology Support Unit (ETSU); May 1999.

[5] Previsic M, Siddiqui O, Bedard R. Economic assessment methodology for offshore wave power plant, tech. rep. EPRI; 2004.

[6] Callaghan J. Future marine energy, tech. rep. Carbon Trust; 2006.

[7] Dalton G, Alcorn R, Lewis T. Case study feasibility analysis of the Pelamis wave energy converter in Ireland, Portugal and North America. Renewable Energy 2009;35:443-55.

[8] Raventos A, Sarmento A, Neumann F, Matos N. Projected deployment and costs of wave energy in Europe. In. 3rd International conference on ocean energy; 2010.

[9] Allan G, Gilmartin M, Mc Gregor P, Swales K. Levelised costs of wave and tida energy in the UK: cost competitiveness and the importance of banded renewables obligation certificates. Energy Policy 2011;39:23-39.

[10] Stallard T, Rothschild R, Aggidis G. A comparative approach to the economic modelling of a large-scale wave power scheme. European Journal of Operational Research 2007; 185:884-98.

[11] Ricci P, Lopez J, Villate JL, Stallard T. Summary of attributes of cost models used by different stakeholders, tech. rep. D 7.1. EquiMar; February 2009.

[12] Menanteau P, Finon D, Lamy M. Prices versus quantities: choosing policies for promoting the development of renewable energy. Energy Policy 2003;31: 799-812.

[13] Weber J, Teillant B, Costello R, Ringwood J, Soulard T. Integrated WEC system optimisation - achieving balanced technology development and economical lifecycle performance. In. 9th European wave and tidal energy conference. Southampton, United Kingdom; 2011.

[14] Stallard T, Johanning L, Smith G, Ricci P, Villate JL, Dhedin JF. Guidelines regarding the variation of infrastructure requirements with scale of deployment, tech. rep. D 7.3.3. Equimar; February 2010.

[15] Graham C. The parameterisation and prediction of wave height and wind speed persistence statistics for oil industry operational planning purposes. Coastal Engineering 1982;6:303-29.

[16] Det Norske Veritas. Modelling and analysis of marine operations, tech. rep. DNV-RP-H103. Det Norske Veritas; 2011.

[17] O'Sullivan D, Dalton G. Challenges in the grid connection of wave energy devices. In. 8th European wave and tidal energy conference. Uppsala, Sweden 2009.

[18] Beels C, Troch P, Kofoed J, Frigaard P, Kringelum J, Kromann P, et al A methodology for production and cost assessment of a farm of wave energy converters. Renewable Energy 2011;36:3402-16.

[19] The Department of Communication. Energy and natural resources of the Republic of Ireland, renewable energy feed-in-tariff, Minister Ryan launches major new ocean energy initiatives; 2009.

[20] Koller T, Goedhart M, Wessels D. Measuring and managing the value of companies. John Willey \& Sons, Inc.; 2005.

[21] U.S. Army Corps of Engineers. Coastal engineering manual (CEM) - part 2: coastal hydrodynamics - chapter II-1: water wave mechanics, tech. rep. EM 1110-2-1100. U.S. Army Corps of Engineers; 2002.

[22] Sharkey F, Bannon E, Colon M, Gaughan K. Dynamic electrical rating and the economics of capacity factor for wave energy converters arrays. In. 9th European wave and tidal energy conference, Southampton, United Kingdom; 2011.

[23] Nolan N, Ringwood J, Holmes B. Short term wave energy variability off the west coast of Ireland. In. 7th European wave and tidal energy conference. Porto, Portugal; 2007. 